\title{
Uma análise de satisfação do uso de um serious game educacional para a simulação de primeiros socorros
}

\author{
Nicolau Calado Jofilsan ${ }^{1}$, Gabriel Candido da Silva', Myrela Dias Barbosa da \\ Silva ${ }^{1}$, Danilo Jose Lopes Silva ${ }^{1}$, Ilton de Araújo Bandeira ${ }^{1}$, Ivaldir de Farias \\ Junior ${ }^{1}$, Ivson Henrique Bezerra dos Santos ${ }^{1}$, Rodrigo José Da Silva ${ }^{1}$ \\ ${ }^{1}$ Faculdade São Miguel, Recife - PE, Brasil \\ \{gabcandidods; daniloklopes; dias.myrela; iltonbandeira1965; ivson.java\}@g \\ mail.com; ncj;ihfj\}@cin.ufpe.br; rodrigosilva.tec@hotmail.com
}

\begin{abstract}
This article aims to describe the process of producing a serious educational game, idealized for learning in institutions of higher learning. Research was done with students of the health courses, which helped to prove direct performance in the improvement of cognitive functions such as memory, attention, perception, among others. The tests were based on a qualitative and quantitative approach, with an exploratory and also statistical character. The usability test was performed by 15 volunteers with a game prototype at a college in Recife, Brazil. From the generated results, we can understand and execute improvements that can be made to a greater identification and interaction of the user with the proposed game.
\end{abstract}

Resumo. Este artigo tem como objetivo descrever a aplicação de um teste de usabilidade de um serious game, idealizado para a aprendizagem nas instituições de ensino superior. Pesquisas foram feitas com alunos dos cursos de saúde, estas, que ajudaram a comprovar o efeito direto no aperfeiçoamento das funções cognitivas como memória, atenção, percepção, entre outras. $O$ estudo foi baseado em uma abordagem qualitativa e quantitativa, com caráter exploratório e também estatístico. O teste de usabilidade foi realizado por 15 voluntários com um protótipo do jogo em uma faculdade no Recife, Brasil. A partir dos resultados gerados, podemos entender e executar melhorias que podem ser feitas para uma maior identificação e interação do usuário com o jogo proposto.

\section{Introdução}

Sabe-se que acidentes são comuns, fazendo-se necessário um preparo prévio de discentes e profissionais de enfermagem, para que esses consigam atuar como agentes ativos de ação frente às situações de urgência e emergência, aplicando de forma correta as técnicas de primeiros socorros, que podem ser definidas como os cuidados imediatos prestados à vítima, antes da chegada de socorro especializado. Capacitar esse público para aquisição de conhecimento acerca de primeiros socorros é a melhor maneira de contribuir na diminuição de sequelas e óbitos decorrentes das causas externas. O uso dos recursos educativos podem facilitar o processo de ensino-aprendizagem e ainda serem prazerosos, interessantes e desafiantes. 
VII Congresso Brasileiro de Informática na Educação (CBIE 2018)

Anais do XXIX Simpósio Brasileiro de Informática na Educação (SBIE 2018)

Para tornar um conteúdo complexo mais prazeroso e engajante de aprender, Lopes et al (2015) e Freitas e Adamatti (2016) relataram em seus estudos que o uso dos jogos facilitam na obtenção de informação combinando o conteúdo com momentos lúdicos e interativos, aumentando a motivação do aprendizado e a fixação do conhecimento. Segundo Sá et al, (2007) "a utilização de jogos nas atividades de ensino possibilita oferecer ao aprendiz momentos lúdicos e interativos como etapas do processo de aprendizagem".

Os jogos são recursos estimulantes de aprendizado, utilizados em várias áreas e níveis de ensino, Souza e Morales (2015). Na enfermagem, os resultados têm demonstrado que tais metodologias ajudam a desenvolver habilidades e competências no relacionamento interpessoal, na autonomia da aprendizagem e no desenvolvimento do pensamento crítico pontuam Gomes, Andrade e Queluci (2013). Tecnologias da informação e comunicação vêm sendo cada vez mais utilizadas na educação com o intuito de facilitar o processo de ensino- aprendizagem, ferramentas como aplicativos e jogos digitais são criados e desenvolvidos para auxiliar na aquisição desse conhecimento, que pode ser facilitada e, até mesmo, divertida.

Há uma grande variedade de inovações tecnológicas que colaboram no desenvolvimento de habilidades clínicas em enfermagem, como simulação, ambientes virtuais de aprendizado e outros materiais didáticos digitais. Na literatura há relatos de que esses recursos tecnológicos dinamizam o ensino, desenvolvem habilidades e conhecimentos capazes de mobilizar atitudes de resolução de problemas. A possibilidade do estudante e do profissional de saúde simular a execução de um cuidado em um ambiente virtual, quantas vezes forem necessárias, auxilia na aquisição e no aperfeiçoamento de habilidades. As tecnologias educacionais digitais são efetivas e estão inseridas cada vez mais no ensino de Enfermagem e existe uma grande diversidade de materiais disponíveis para utilização, desta forma contribuindo com a formação em saúde.

Assim, este artigo tem como objetivo a criação de um jogo digital educacional, avaliar a usabilidade do mesmo e descrever a opinião e satisfação do público alvo na utilização do jogo como suporte tecnológico para o processo ensino-aprendizado que auxilie na tomada de decisões em ações de primeiros socorros.

\section{Fundamentação Teórica}

\subsection{Educação e Saúde}

A prática da Educação em Saúde visa contribuir para que as pessoas adquiram autonomia para identificar e utilizar as formas e os meios para preservar e melhorar a sua vida. É uma atividade que requer grande atenção dos profissionais por sua magnitude, e deve ser entendida como uma importante vertente à prevenção, preocupada com a melhoria das condições de vida e de saúde das populações. A abordagem construtiva de educação em saúde está diretamente relacionada à aprendizagem.

A falta de conhecimento da população em geral, em situações de emergências, pode ocasionar inúmeros agravos à saúde. Condutas incorretas com a vítima, entre outras situações, podem agravar ainda mais o caso. No Brasil, mais de 13\% do total de mortes são decorrentes de acidentes, correspondendo como a terceira causa de óbito na 
VII Congresso Brasileiro de Informática na Educação (CBIE 2018)

Anais do XXIX Simpósio Brasileiro de Informática na Educação (SBIE 2018)

população. Dentre os acidentes que acometem as crianças os mais comuns são: choque elétrico, queimaduras, afogamento, asfixia, ingestão de objetos pequenos, quedas, acidentes com pipas e fogos de artifício e também acidentes de trânsito. Em adultos, as principais causas de morte em acidentes são geralmente por traumas ocasionados por acidentes automobilísticos, por arma de fogo e arma branca, Blank (2001).

Sabe-se que a educação é um processo de constante troca, atuando como meio de transformação e reestruturação de condutas que oportunizem ambientes saudáveis. Em muitas situações a falta de conhecimento por parte da população ocasiona inúmeros problemas, como o estado de pânico ao ver o acidentado, a manipulação incorreta da vítima e ainda a solicitação excessiva e às vezes desnecessária do socorro especializado.

As escolas têm um papel eficaz e crescente na promoção de saúde, na prevenção de doenças e de acidentes Fioruc et al. (2008). Porém, tendo em vista a quantidade de agravos à saúde que acontecem no Brasil, o ensino de primeiros socorros ainda é pouco difundido, prevalecendo o desconhecimento sobre o tema Pergola e Araújo (2008).

\subsection{Tecnologia e Jogos Educacionais}

Em uma época em que as tecnologias estão por toda parte, demandando um desenvolvimento nos saberes de diferentes áreas, a escola se mostra atrasada em relação às mudanças que ocorrem, tornando-a falha em preparar os jovens para a sociedade atual, Paula e Valente (2015). A tecnologia, posta à disposição de estudantes, contribui para o desenvolvimento individual, tanto cognitivo quanto estético, através das múltiplas utilizações que o docente pode realizar nos espaços de interação grupal. Desconhecer as possibilidades que a tecnologia, o saber tecnológico e as produções tecnológicas trazem na vida cotidiana dos estudantes nos fariam retroceder a um ensino que, não seria tradicional, e sim, ficcional, afirma Litwin (1997).

Os jogos de computador são muito populares entre crianças e adolescentes. Aproveitando-se dessa proximidade, empresas que desenvolvem material didático começaram a desenvolver jogos com objetivos educacionais, buscando auxiliar a transferência do conhecimento, Fernandes (2010). O interesse no uso dessa categoria de jogos na educação tem aumentado cada vez mais e em diversas áreas, apoiando-se na ideia de que eles possuem um enorme potencial educacional devido a sua capacidade de engajar os jogadores através de seus desafios e sistemas de recompensas Paula e Valente (2015).

Na concepção de Piaget apud Faria (1995), os jogos significam uma assimilação funcional do indivíduo, em um exercício de atos individuais já adquiridos, gerando ainda uma sensação de prazer pelas ações lúdicas em si e pelas ações em que o próprio indivíduo já domina. Concluindo-se que os jogos atuam em duas funções: estabelecer os sentidos e competências já formadas e proporcionar equilíbrio emocional para o jogador utilizando sistemas de penalidades e recompensas.

\section{Metodologia}

A metodologia usada na pesquisa foi do tipo qualitativa e quantitativa através de uma análise de usabilidade e percepção do usuário. A análise qualitativa foi feita a partir da captura por vídeo, onde foi realizada a procura por dados relevantes de maneira observacional obtidos da experiência dos usuários ao utilizarem o produto. A análise 
VII Congresso Brasileiro de Informática na Educação (CBIE 2018)

Anais do XXIX Simpósio Brasileiro de Informática na Educação (SBIE 2018)

quantitativa foi feita através da efetividade, tempo de uso e percepção do usuário através do questionário AttrackDiff.

O AttrakDiff constitui um instrumento para medir a atratividade de produtos interativos com foco na experiência do usuário. Este instrumento utiliza uma escala de diferencial semântico composta por pares de adjetivos opostos. Através desta escala o usuário pode expressar sua percepção sobre o produto. Esses adjetivos estão agrupados em quatro dimensões avaliativas descritas abaixo:

- Qualidade pragmática PQ: Descreve a usabilidade de um produto e indica como os usuários alcançam seus objetivos ao usar o produto;

- Qualidade hedônica - Estimulação HQ-S: Essa dimensão explora o potencial evolutivo do produto. Ela indica até que ponto o produto pode suportar as necessidades de usuário em termos de inovação, interesse e funções estimulantes, conteúdo e estilos de Interação e apresentação;

- Qualidade hedônica - Identidade HQ-I: Essa dimensão indica até que ponto o produto permite ao usuário se identificar com ele;

- Atratividade ATT: Representa através de um valor global a qualidade do produto percebida pelo usuário.

Faz-se importante destacar que a qualidade hedônica e a pragmática são dimensões independentes, mas as duas contribuem para mensurar a atratividade. Assim, é capaz de medir a percepção do usuário a partir das dimensões: Qualidade Pragmática (QP) que é a qualidade da aplicação e os objetivos desejados alcançados pelo usuário; Qualidade Hedônica que se divide em Estímulo (QH-S) que mostra até que ponto o produto foi capaz de atender as necessidades e trazer interesse ou motivação ao usuário e Qualidade Hedônica de Identidade (QH-I) que busca perceber até que ponto o usuário foi capaz de se identificar com o produto testado; Atratividade (ATT) que baseada na percepção de qualidade dará uma indicação do valor geral da aplicação, Silva e Jofilsan et al. (2018), Lemos, Júnior e Filho (2017).

\subsection{Cenário}

A avaliação foi realizada com a participação voluntária de 15 alunos da área de saúde pertencentes aos cursos de enfermagem e farmácia da Faculdade São Miguel, cidade: Recife, estado: Pernambuco. Dos 15 alunos voluntários tivemos nove mulheres e seis homens, treze deles com idade entre vinte a trinta e nove anos e dois deles com idade entre cinquenta a sessenta anos. O teste aconteceu durante os dias 26 e 29 de junho e foi dividido em 3 etapas: (1) Foi solicitado para o participante jogar por tempo livre sem interferência dos aplicadores do teste, utilizando a técnica Think Aloud que consiste em deixar o usuário falar tudo que pensa enquanto utiliza o produto; (2) Após utilizar o jogo foi perguntado se o participante gostaria de comentar a sua experiência e se teria críticas ou sugestões de melhoria; (3) O preenchimento do questionário do AttrackDiff para que seja realizada a identificação de problemas de usabilidade, a análise da experiência do usuário e a satisfação com o produto. 
VII Congresso Brasileiro de Informática na Educação (CBIE 2018)

Anais do XXIX Simpósio Brasileiro de Informática na Educação (SBIE 2018)

\section{Resultados}

\subsection{Descrição do Jogo Sério}

O jogo possui o intuito de auxiliar no aprendizado do tratamento em situações de primeiros socorros para alunos do ensino superior ou técnico das áreas de saúde. O jogo foi desenvolvido utilizando o Unity e possui gráficos 3D. O gameplay é baseado em um sistema de tomada de decisões onde o jogador, em determinados momentos, pode escolher as ações do seu personagem entre duas alternativas na tentativa de ajudar uma vítima que estará passando por um problema relacionado a primeiros socorros.

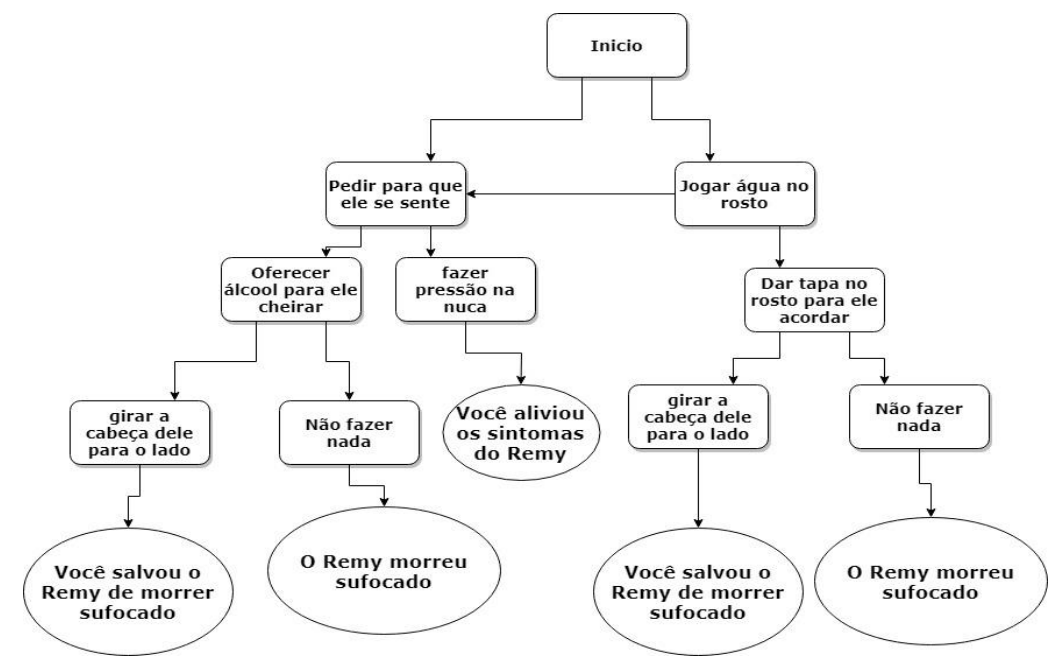

Figura 1. Fluxograma da árvore de decisão do jogo

O jogo segue os caminhos apresentados no fluxograma (Figura 1), seguindo percursos diferentes a partir das decisões tomadas pelo jogador durante o gameplay. Essas decisões acabam acarretando em salvar ou não a vida do personagem que neste caso, está sofrendo de uma crise de vertigem. As decisões utilizadas no jogo foram retiradas da bibliografia específica que trata de casos de vertigens e desmaios (Manual de Primeiros Socorros, IFSRG, 2017).
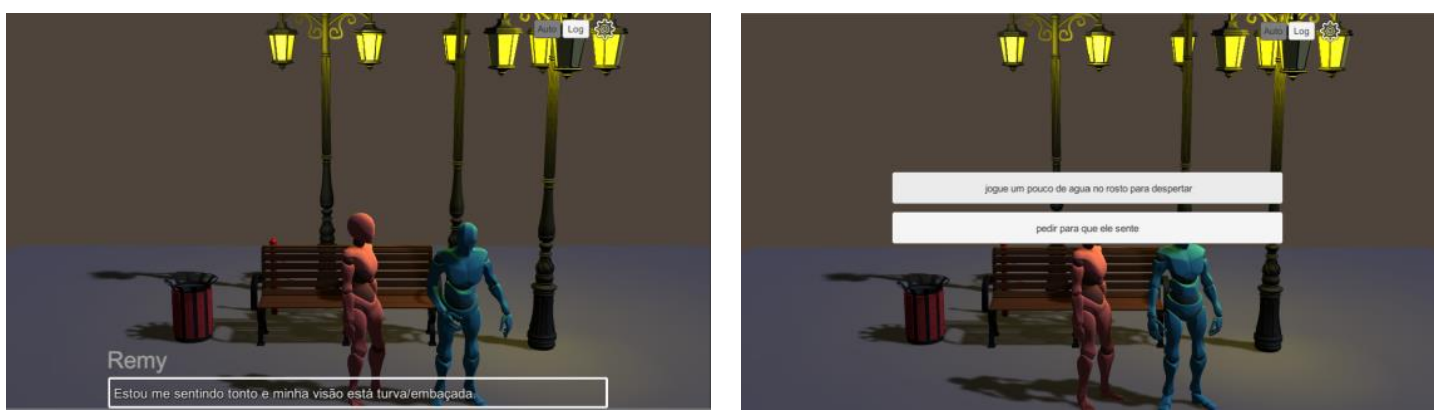

Figura 2. Fluxograma da árvore de decisão do jogo

O objetivo do jogador é conseguir identificar por qual problema a vítima está passando, a partir de dicas deixadas nos diálogos e em suas animações, para que possa tomar as decisões corretas e por fim realizar o tratamento de maneira adequada. Para jogar é utilizado o mouse, clicando com o botão esquerdo no campo onde surgem os diálogos, que fica na parte inferior da tela. Em momentos específicos, o jogador pode 
VII Congresso Brasileiro de Informática na Educação (CBIE 2018)

Anais do XXIX Simpósio Brasileiro de Informática na Educação (SBIE 2018)

selecionar as decisões que são exibidas em botões que surgem na tela a cada momento chave. As condições de vitória e derrota dependem da sequência de decisões tomadas

pelo jogador. É possível chegar a uma condição de vitória, ajudando o personagem que sofre uma crise de vertigem a melhorar, mesmo não tomando todas as decisões corretas. A condição de derrota é alcançada tomando todas as decisões erradas ou sendo negligente aos sintomas do personagem Remy. O jogo buscou representar uma situação comum, que exige conhecimentos básicos de primeiros socorros, para proporcionar ao estudante do curso de saúde uma imersão interativa e divertida no assunto que geralmente é estudado de forma tradicional.

\subsection{Avaliação de Usabilidade}

Os principais problemas identificados pelos usuários foram a falta de menus, setas, botões e elementos de interface que facilitassem identificar como deveriam interagir com o jogo. As áreas destinadas para a interação foram os textos, na parte inferior da tela, e os botões com as alternativas possíveis de se tomar em momentos específicos da história. Foi comum entre os participantes tentar clicar nos personagens em busca de algum tipo de reação como levantar ou mover-se até o banco da praça, por exemplo.

Três dos participantes sugeriram a utilização de algum tipo de tutorial no início do jogo, isso pode ter relação com a avaliação da qualidade pragmática, mais baixa entre as quatro dimensões do attrakdiff. Isso significa que a usabilidade (PQ), mesmo tendo o valor positivo de 1,04, precisa melhorar significativamente ao ponto de deixar o jogo intuitivo sem a necessidade de tutoriais ou instruções excessivas. Outra observação importante foi a falta de mais opções na tomada de decisão. Cinco dos participantes criticaram não existir mais de duas possibilidades de escolha em cada momento específico da história, um deles pontuou que o interessante seria ter cinco possibilidades de escolha enquanto outro participante disse que gostaria de poder falar ou digitar as ações que gostaria de tomar.

Os feedbacks das tomadas de decisão não ficaram claros para os participantes. Uma crítica severa ao jogo foi o fato de, ao escolher uma das decisões disponíveis, não ficar claro para o usuário se aquela decisão gerou um resultado positivo ou negativo, se o paciente melhora ou piora após uma determinada decisão. Isso afeta o entendimento das condições de vitória e derrota do jogo como também prejudica o treinamento do aluno em situações de primeiros socorros por deixar confuso quais seriam as ações certas e erradas em uma situação de vertigem e desmaio de um paciente. "O jogo também poderia ter som, diálogos falados para facilitar o entendimento das situações", contribuiu um dos participantes. 
VII Congresso Brasileiro de Informática na Educação (CBIE 2018)

Anais do XXIX Simpósio Brasileiro de Informática na Educação (SBIE 2018)

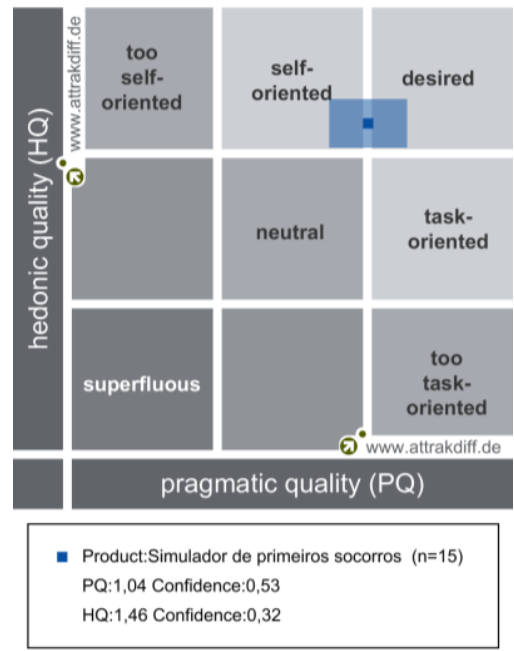

Figura 3. Portfólio de Resultados

Tendo como base o gráfico de Portfólio de resultados (Figura 3), podemos considerar que o resultado teve boa confiabilidade, retângulo azul transparente, com 0,53 para a qualidade pragmática e 0,32 para a qualidade hedônica. Isso mostra que as respostas tiveram similaridade entre os participantes. $O$ resultado da qualidade pragmática teve valor 1,04 e o da qualidade hedônica teve valor 1,46 posicionando o produto entre os quadrantes auto-orientado e desejado o que denota um produto atraente que necessita de melhorias em sua usabilidade.

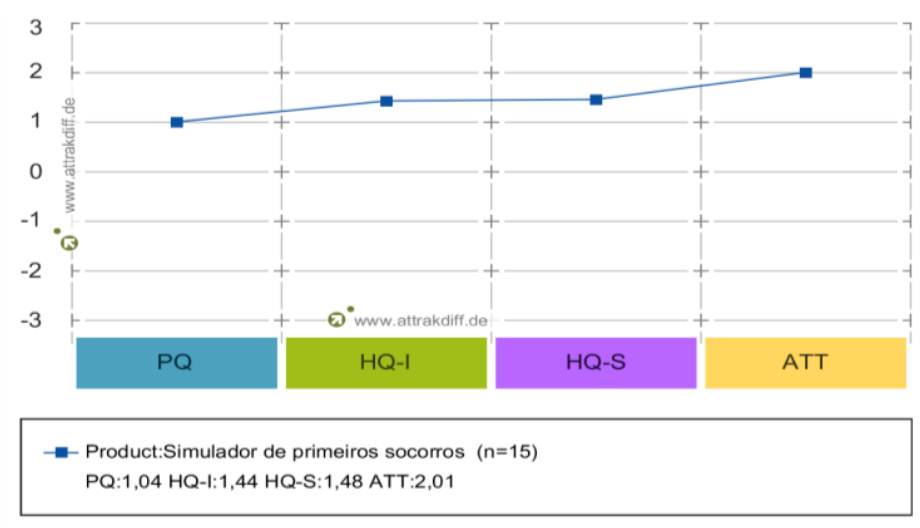

Figura 4. Diagrama da Média de Valores

Com base neste gráfico de Diagrama da Média de Valores (Figura 4) é perceptível que o jogo sério teve uma avaliação positiva em seu uso e jogabilidade, tendo atingido uma pontuação de 1,04 na Qualidade Pragmática (PQ). No entanto, foi possível notar que a imprevisibilidade acabou afetando negativamente a experiência dos usuários, deixando-os confusos em relação aos feedbacks de suas decisões. A falta de clareza dos elementos de interação na interface também foi responsável por esse resultado da Qualidade Pragmática, que teve avaliação inferior ao das outras dimensões.

Na Qualidade Hedônica de Identidade (HQ-I), obtivemos uma pontuação de 1,44 destacando o sentimento de integração e aproximação que os usuários tiveram ao testar o produto, devido a interatividade que foi possível ser construída no jogo ao dar as tomadas de decisão em uma situação de primeiros socorros ao usuário. 
VII Congresso Brasileiro de Informática na Educação (CBIE 2018)

Anais do XXIX Simpósio Brasileiro de Informática na Educação (SBIE 2018)

A Qualidade Hedônica de Estímulo (HQ-S) obteve uma pontuação de 1,48 onde foi possível notar um destaque na criatividade, por se tratar de um jogo que busca apresentar um conteúdo que pode ser desestimulante quando abordado de forma tradicional, em um produto interativo que possui a proposta de criar uso e aprendizado prático.

Por fim, temos a Atratividade (ATT), que atingiu a ótima pontuação de 2,01 e obteve em todas as suas características um resultado bastante positivo, mostrando que os usuários que testaram o produto notam um enorme valor em sua aplicação.

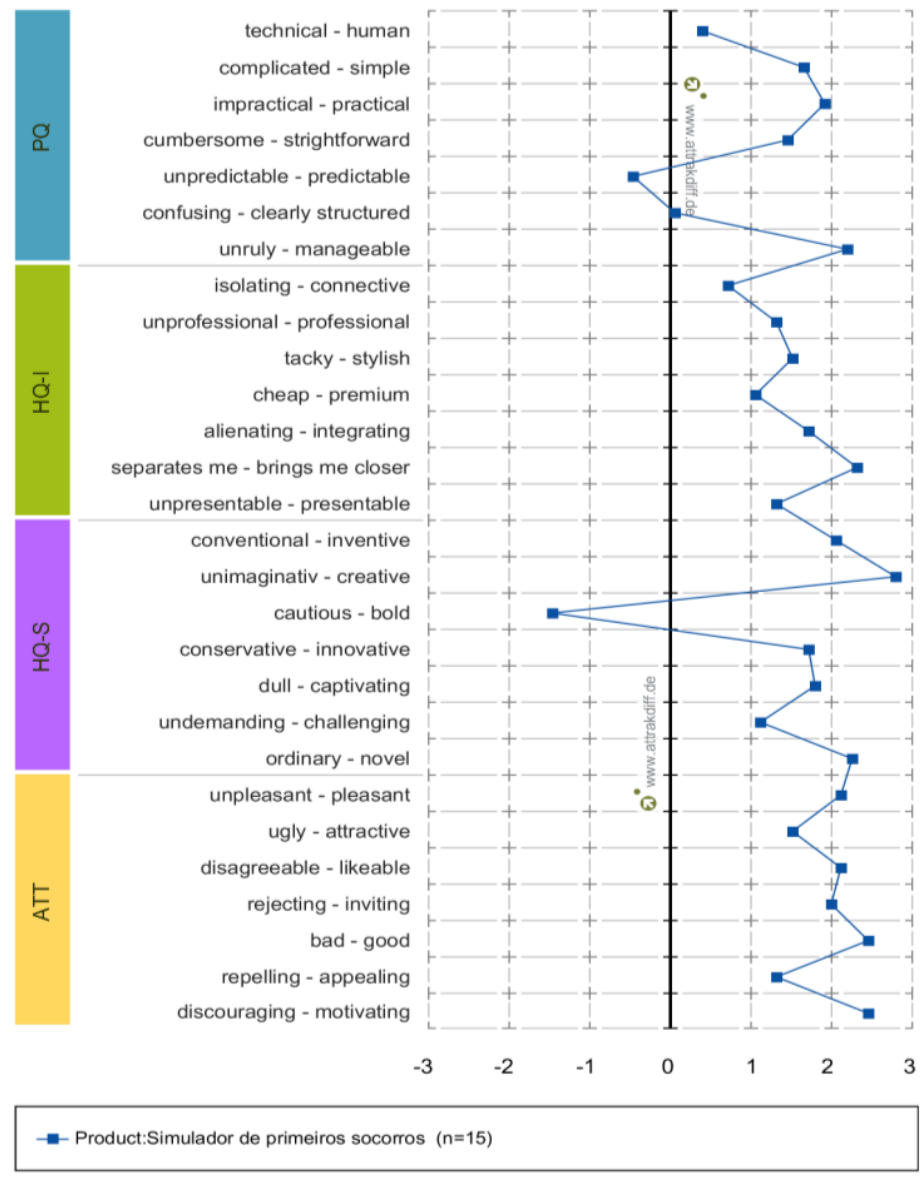

Figura 5. Descrição dos Pares de Palavras

De acordo com o gráfico da Descrição de Palavras - Pares (Figura 5), é possível observar que os itens "Cauteloso - Ousado" e "Imprevisível - Previsível" obtiveram valores negativos (abaixo de zero), isso deve-se ao fato do jogo ser focado em tomada de decisões, o que torna sua jogabilidade mais limitada. Situações reais de primeiros socorros podem exigir uma interatividade mais ousada para que a simulação seja mais imersiva. A imprevisibilidade está relacionada a falta de clareza na forma como o usuário podia interagir com o jogo. Os elementos de interface e o que o jogador deve fazer precisam ficar mais previsíveis. Por outro lado os pontos "Sem Criatividade Criativo", "Ruim - Bom" e "Desmotivador - Motivador" obtiveram ótima pontuação, mostrando que a experiência vivenciada com o conteúdo proposto através do jogo foi prazerosa e motivadora. 
VII Congresso Brasileiro de Informática na Educação (CBIE 2018)

Anais do XXIX Simpósio Brasileiro de Informática na Educação (SBIE 2018)

\section{Conclusão}

Com o desenvolvimento deste trabalho, foi possível para os integrantes da equipe o entendimento de forma completa de como elaborar um jogo sério utilizando as tecnologias disponíveis, levando em consideração a importância da aplicação correta e de como deve ser utilizado tais materiais propostos para fins metodológicos.

Graças a coleta de sugestões e críticas dos voluntários descobrimos que nossas opções de desenvolvimento são muito mais amplas e diversificadas e que o possível alcance bem sucedido ao nosso público alvo em si traz uma nova perspectiva de trabalho e planejamento.

Após o término das pesquisas realizadas, foi percebido o quão importante é o uso da tecnologia no processo de aprendizagem para promover uma melhor educação e estimulação e o quão vasto são suas vantagens quando aplicadas no processo pedagógico, sempre procurando o desenvolvimento de competências e habilidades do indivíduo.

\section{Referências}

Blank, D. (2001) Promoção de segurança do pedestre na infância e adolescência. Disponível em: $<$ http://www.sbp.com.br/img/documentos/doc_promocao_seguranca2.pdf $>$. Acesso em: ago. 2016.

Cavalcante, S. N.; Morais, H. C. C. (2016) Tecnologia em saúde sobre o tratamento de feridas: estratégia educativa na monitoria de enfermagem. Encontro de Extensão, Docência e Iniciação Científica (EEDIC), Centro Universitário Católica de Quixadá, dez., 2016.2 Disponível em: $<$ http://publicacoesacademicas.fcrs.edu.br/index.php/eedic/article/view/968/711>. Acesso em: jun, 2018.

Faria, A. R. (1995) O desenvolvimento da criança e do adolescente segundo Piaget. Ed. Ática. $3^{\circ}$ edição, 1995, São Paulo-SP.

Fernandes, J. C. L. (2010) Educação digital: Utilização dos jogos de computador como ferramenta de auxilio à aprendizagem. Periódico Eletrônico da FATEC-São Caetano do Sul, São Caetano do Sul, v.1, n. 3, Jul./Dez. 2010, p. 88 a 97. Disponível em: $<$ https://www.fatecsaocaetano.edu.br/fascitech/index.php/fascitech/article/view/29>. Acesso em: jun, 2018.

Fioruc, B. E.; Molina A. C., Junior WV, Lima SAM.(2008) Educação em saúde: abordando primeiros socorros em escolas públicas no interior de São Paulo. Rev. Eletr. Enf. [Internet]. 2008;10(3):695-702. Disponível em: $<$ https://www.fen.ufg.br/revista/v10/n3/pdf/v10n3a15.pdf $>$ Acesso em: 04 mai. 2018.

Freitas, V., \& Adamatti, D. (2016). Educa Direito: A Serious Game for the Teaching of Labor Law. Brazilian Journal of Computers in Education, 24(03), 1. doi:http://dx.doi.org/10.5753/rbie.2016.24.3.1 
VII Congresso Brasileiro de Informática na Educação (CBIE 2018)

Anais do XXIX Simpósio Brasileiro de Informática na Educação (SBIE 2018)

Gomes, D. M.; Andrade, G. S.; Queluci, G. C. (2013) Metodologias ativas aplicabilidades no ensino de Enfermagem. Natal, RN, $17^{\circ}$ Seminário Nacional de Pesquisa em Enfermagem, junho de 2013.

Lemos, W. B., Júnior, I. H. F., Filho, A. S. C. (2017) Uma proposta de um serious games no auxílio do aprendizado da anatomia humana. VI Congresso Brasileiro de Informática na Educação (CBIE 2017). Disponível em: <http://www.brie.org/pub/index.php/sbie/article/view/7594/5390>. Acesso em: jun, 2018.

Litwin, E. (1997) Tecnologia Educacional: Politica, Histórias e Propostas. Ed. Artes Médicas 1997, Guarapuava-PR.

Lopes, R. A.; Toda, A. M.; Brancher, J. D. (2015) Um estudo preliminar sobre elementos extrínsecos e intrínsecos do processo de Gamification. Revista Brasileira de Informática na Educação, Volume 23, № 03.

Mesquita, T. M., Albuquerque R. S. et al. (2017) Recurso educativo em primeiros socorros no processo ensino-aprendizagem em crianças de uma escola pública. Revista Ciência Plural. 2017; 3 (1): 35-50. Disponível em: < https://periodicos.ufrn.br/rcp/article/download/11464/8587>. Acesso em: jun, 2018.

Nardino J., Badke M. R. et al. (2012) Atividades educativas em primeiros socorros. Rev. contexto \& saúde, editora: UNIJUÍ, v.12, n.23, jul./dez. 2012, p. 88-92, Ijuí. Disponível em: $<$ https://www.revistas.unijui.edu.br/index.php/contextoesaude/article/view/949>. Acesso em: jun/2018.

Paula, B. H., Valente, J.A. (2015) Jogos digitais e educação: uma possibilidade de mudança da abordagem pedagógica no ensino formal. Revista Ibero-americana de Educação, vol. 70, núm 1, pp. 9-28, 2015. Disponível em: $<$ https://rieoei.org/historico/deloslectores/6977.pdf>. Acesso em: jun, 2018.

Pergola, A. M., Araujo, I. E. M. (2008) O leigo em situação de emergência. Rev. esc. enferm. USP [online]. 2008, vol.42, n.4, pp.769-776. ISSN 0080-6234. http://dx.doi.org/10.1590/S0080-62342008000400021.

Sá, E. J. V; Teixeira, J. S. F; Fernandes, C. T (2007) Design de Atividades de Aprendizagem que Usam Jogos como Princípio para Cooperação. In: Anais Do Xviii Simpósio Brasileiro De Informática Na Educação (Sbie), São Paulo - Sp, Brasil

Silva G. C., Jofilsan N. C. et al. (2018) Satisfaction Analysis for Using Educational Serious Games for Teaching Wound Treatment. The 9th International Conference on Applied Human Factors and Ergonomics (AHFE 2018). Acesso em: jun, 2018

Silveira, M. S., Cogo, A. L. P. (2017) Contribuições das tecnologias educacionais digitais no ensino de habilidades de enfermagem: revisão integrativa. Rev. Gaúcha Enferm., vol.38, n.2, Porto Alegre, 2017. Disponível em: $<$ http://www.scielo.br/scielo.php?script=sci_arttext\&pid=S198314472017000200501>. Acesso em: jun, 2018.

Souza, C. A.; Morales, O. E. T. (2015) (orgs.). Coleção Mídias Contemporâneas. Convergências Midiáticas, Educação e Cidadania: aproximações jovens. Vol. II. PG: Foca Foto-PROEX/UEPG, 2015. 